\title{
Characterization of TiCN Thin Films Deposited by Dc-Pulsed PACVD Using Methane Precursor
}

\author{
Seyed Mohammad Mahdi Shafiei ${ }^{a *}$, Mehdi Divandaria, \\ Seyed Mohammad Ali Boutorabi ${ }^{a, b}$, Rahim Naghizadeh ${ }^{a}$ \\ ${ }^{a}$ School of Metallurgical Engineering, Iran University of Science and Technology, \\ Narmak, 1684613114, Tehran, Iran \\ ${ }^{b}$ Center of Excellence for High Strength Alloys Technology - CEHSAT, \\ University of Science and Technology, Narmak, Tehran, Iran
}

Received: July 15, 2014; Revised: November 12, 2014

\begin{abstract}
Titanium carbonitride (TiCN) thin films were deposited on hot-work steel (DIN 1.2606) by plasmaassisted chemical vapor deposition (PACVD) and the influence of different $\mathrm{CH}_{4} /\left(\mathrm{CH}_{4}+\mathrm{N}_{2}\right)$ gas flow ratio, on the layer mechanical properties, were investigated. SEM studies indicated that the growth rate is decreased by increasing the $\mathrm{CH}_{4} /\left(\mathrm{CH}_{4}+\mathrm{N}_{2}\right)$ gas flow ratio. It was found that the $\mathrm{Ti}(\mathrm{C}, \mathrm{N})$ layers have different stoichiometry, $\mathrm{TiC}_{30} \mathrm{~N}_{70}$ and $\mathrm{TiC}_{70} \mathrm{~N}_{30}$ for 0.5 and 0.66 gas flow ratio. Grazing incidence $\mathrm{x}$-ray diffraction (GIXRD), X-ray Photoelectron spectroscopy (XPS), scanning electron microscopy (SEM) and atomic force microscopy (AFM) were used to evaluate the microstructures as well as the morphological property such as roughness. It was also revealed that by increasing the flow ratio, the grain size of the TiCN thin films is increased. A hardness of $2180 \mathrm{HV}_{0.05}$ was obtained when the layer was fabricated at the lower flow ratios.
\end{abstract}

Keywords: $P A C V D, T i C N$, tribology, thin film

\section{Introduction}

DIN $1.2606(\mathrm{X} 4 \mathrm{Cr} 5 \mathrm{MoWSiV})$ steel is currently one of frequently used chromium-molybdenum tool steels, which contains high molybdenum content. This steel has various applications, such as hot forging dies, slotting tools, scissors, hot forging punches, etc. The mechanical, friction and wear properties of it have been extensively investigated as a function of tempering treatment and associated microstructure ${ }^{1,2}$.

The PACVD technique is an appropriate method to deposit wear and corrosion resistant hard coatings which have excellent properties applicable for several applications. In comparison to PVD methods, it offers the possibility of homogeneous coating on work pieces with complicated shapes. Other advantages of PACVD method are high adhesion and good morphology of the layers. Tools deposited with hard coatings, like TiN, TiCN, TiC, have already been used successfully for many industrial application $^{3-6}$. The PACVD process is affected by several process parameters, like discharge voltage, current density, gas pressure, gas composition and flow rate ${ }^{7-9}$.

In the present research, the influence of the $\mathrm{CH}_{4} /$ $\left(\mathrm{CH}_{4}+\mathrm{N}_{2}\right)$ gas flow ratio on characteristics of PACVD TiCN thin film on the hot - work tool steel has been investigated.

\section{Experimental Procedure}

TiCN coatings with compositional gradients were deposited on a X4Cr5MoWSiV hot-work tool steel substrate

*e-mail: shafiei@iust.ac.ir using a PACVD coating system equipped with a voltagecontrolled pulse generator.

During coating, process parameters such as gas flow ratio, wall temperature, voltage duration of pulse-on and pulse-off time and total pressure were monitored. $\mathrm{H}_{2}, \mathrm{Ar}$, $\mathrm{N}_{2}$ and $\mathrm{CH}_{4}$ gases and $\mathrm{TiCl}_{4}$ vapor were used as process gases for coating deposition. Total pressure was kept at 2 mbar and substrate temperature was controlled at $470^{\circ} \mathrm{C}$ to avoid exceeding the tempering temperature of the hot-work tool steel. Plasma nitriding was used as a pre-treatment to decrease hardness gradient between substrate and coating.

The processing parameters for the plasma nitriding are listed in Table 1. The $\mathrm{N}_{2} / \mathrm{CH}_{4}$ gas flow ratio was defined $\mathrm{CH}_{4} /\left(\mathrm{CH}_{4}+\mathrm{N}_{2}\right)$. The crystalline structure of the coatings was determined by grazing incidence $\mathrm{X}$-ray diffraction (GIXRD) in the continuous scanning mode using $\mathrm{CuK}_{\alpha}$ radiation $(\lambda=$ $0.154056 \mathrm{~nm}$ ). The full-width at half-maximum (FWHM) of the Bragg peaks is used to estimate the grain size based on Scherrer formula (Equation 1) ${ }^{10}$ :

$$
D=0.9 \lambda / \beta \cdot \operatorname{COS} \theta
$$

Where $\mathrm{D}$ is grain size, $\beta$ is the FWHM of the Bragg peak, and $\theta$ is the Bragg reflection angle. The chemical composition of the film was analyzed by $\mathrm{x}$-ray photoelectron spectroscopy (XPS) with monochromated AlK $\alpha$ radiation at the pass energy of $1486.6 \mathrm{eV}$. The film morphology was studied by scanning electron microscopy (SEM, VEGATESCAN-XMU) and atomic force microscopy (AFM, 
DME-DS-95-50E). The Vickers hardness of the TiCN coatings was measured using a micro-hardness test, within the loading range of $50 \mathrm{~g}$; five micro-hardness tests were performed for each sample to obtain the average values of the hardness.

Table 1. PACVD parameters.

\begin{tabular}{lc}
\hline \multicolumn{1}{c}{ Parameters } & Value \\
\hline Pulsed voltage & $650 \mathrm{~V}$ \\
Duty cycle & $33 \%$ \\
Temperature & $470^{\circ} \mathrm{C}$ \\
PACVD time & $120 \mathrm{~min}$ \\
$\mathrm{CH}_{4} /\left(\mathrm{CH}_{4}+\mathrm{N}_{2}\right)$ flow ratio & $50 \%, 66 \%$ \\
Total pressure & $2 \mathrm{mbar}$ \\
nitriding time & $120 \mathrm{~min}$ \\
nitriding temperature & $470^{\circ} \mathrm{C}$ \\
\hline
\end{tabular}

\section{Results and Discussions}

Figure 1 illustrates the GIXRD patterns of the coatings deposited at $470{ }^{\circ} \mathrm{C}$ using the two gas mixtures. The (200) plane is revealed to be the preferred structure, deposited via kinetics-limited crystal growth ${ }^{11}$ and under thermodynamically stable conditions because the (200) plane has the lowest energy surface in the TiCN crystal. This implies that the film structure is dense because the plane (200) orientation is the densely packed plane. The GIXRD pattern also indicates an exclusively face-center-cubic (FCC) structure which is closely related to Ti. Nitrogen and Carbon can be incorporated on the octahedral sites of both the hexagonal close-packed lattice of titanium and the FCC sublattice in $\mathrm{TiCN}$ and thus form $\mathrm{TiC}_{\mathrm{x}} \mathrm{N}_{\mathrm{y}}$. In stoichiometric $\mathrm{TiCN}$, it is assumed that all the octahedral sites are filled with nitrogen and carbon ${ }^{12}$.

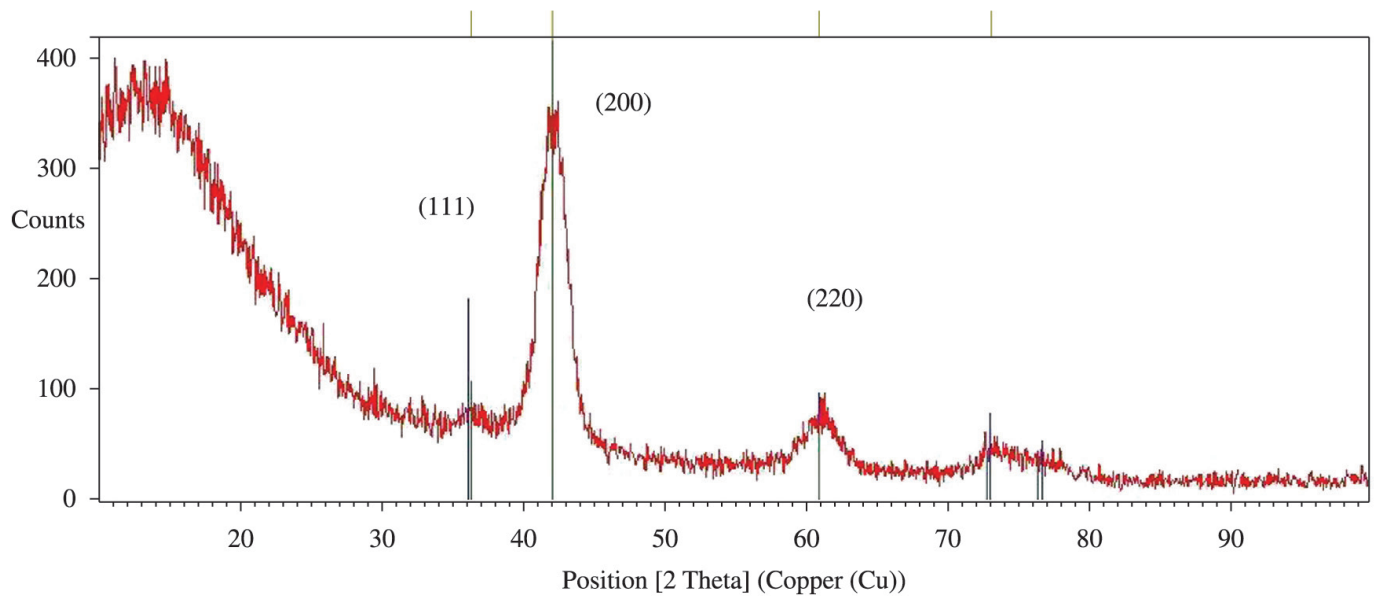

(a)

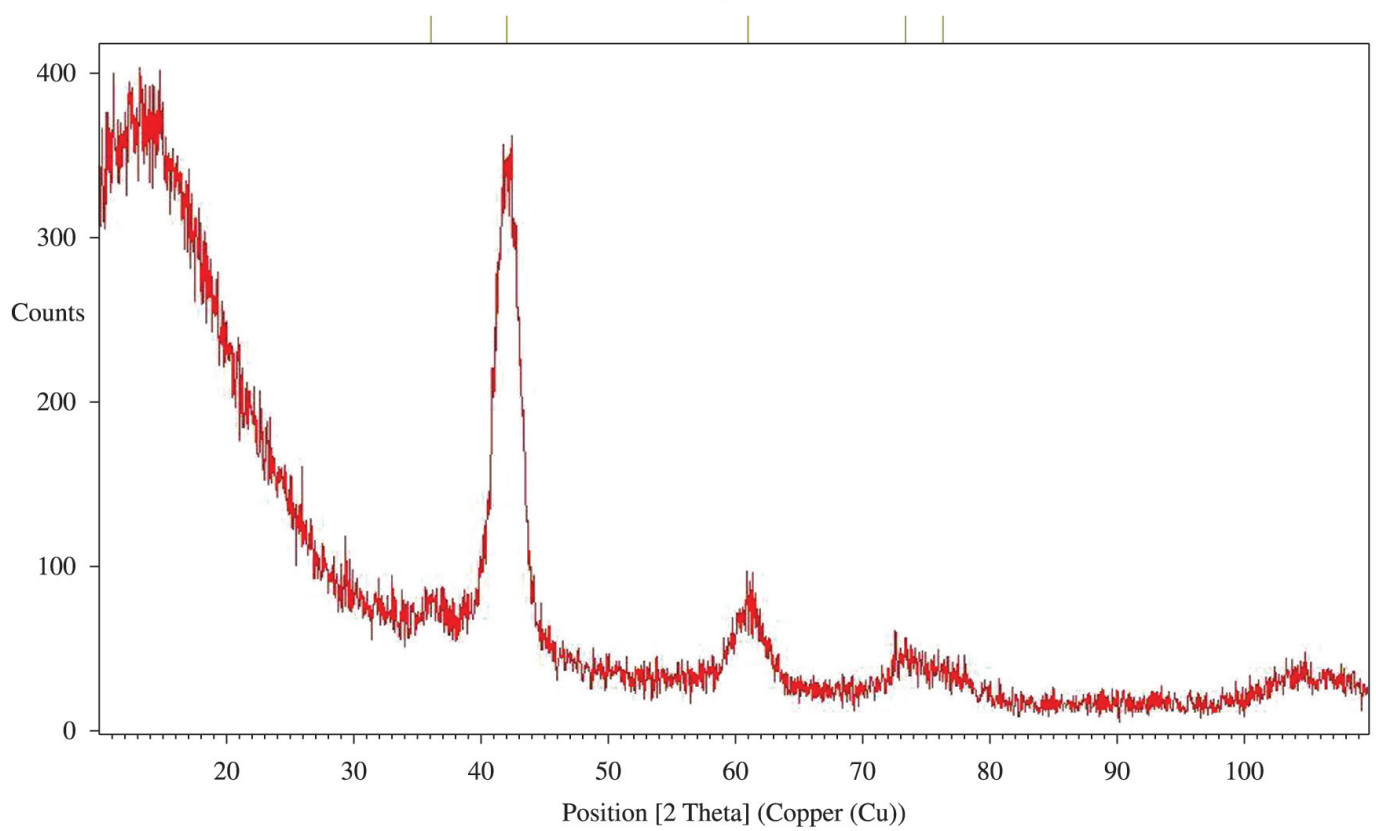

(b)

Figure 1. GIXRD patterns acquired from the TiCxNy coatings using the two gas mixtures $\mathrm{CH} 4 /(\mathrm{CH} 4+\mathrm{N} 2)$. a) 0.66 and b)0.5. 
Titanium carbonitride is a compound stoichiometry of which in $\operatorname{TiC}_{\mathrm{x}} \mathrm{N}_{\mathrm{y}}$ can vary in the range of $0<\mathrm{x}, \mathrm{y}<1$. Moreover, the peaks of the TiCN phase shift to lower angles ${ }^{13}$ and are close to the $\mathrm{TiC}$ phase while the $\mathrm{C}$ relative contents reach around 45 at $\%$ measured by XPS. This is ascribed to the substitution of $\mathrm{N}$ atoms with the bigger $\mathrm{C}$ atoms in the solid solution.

Figure 1 also indicates that by increasing the flow ratio from $50 \%$ to $66 \%$, the (220) plane is thermodynamically stable relative to the (200) plane and the broad peak of

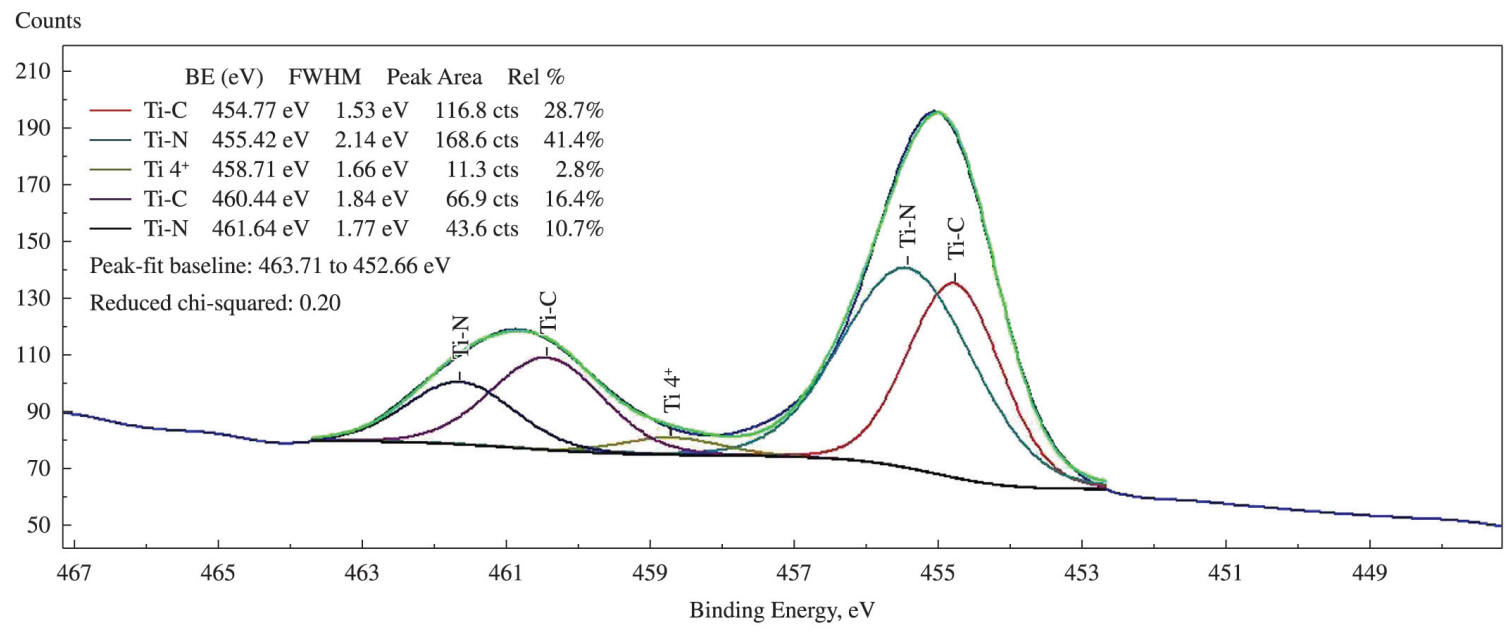

Counts

(a)

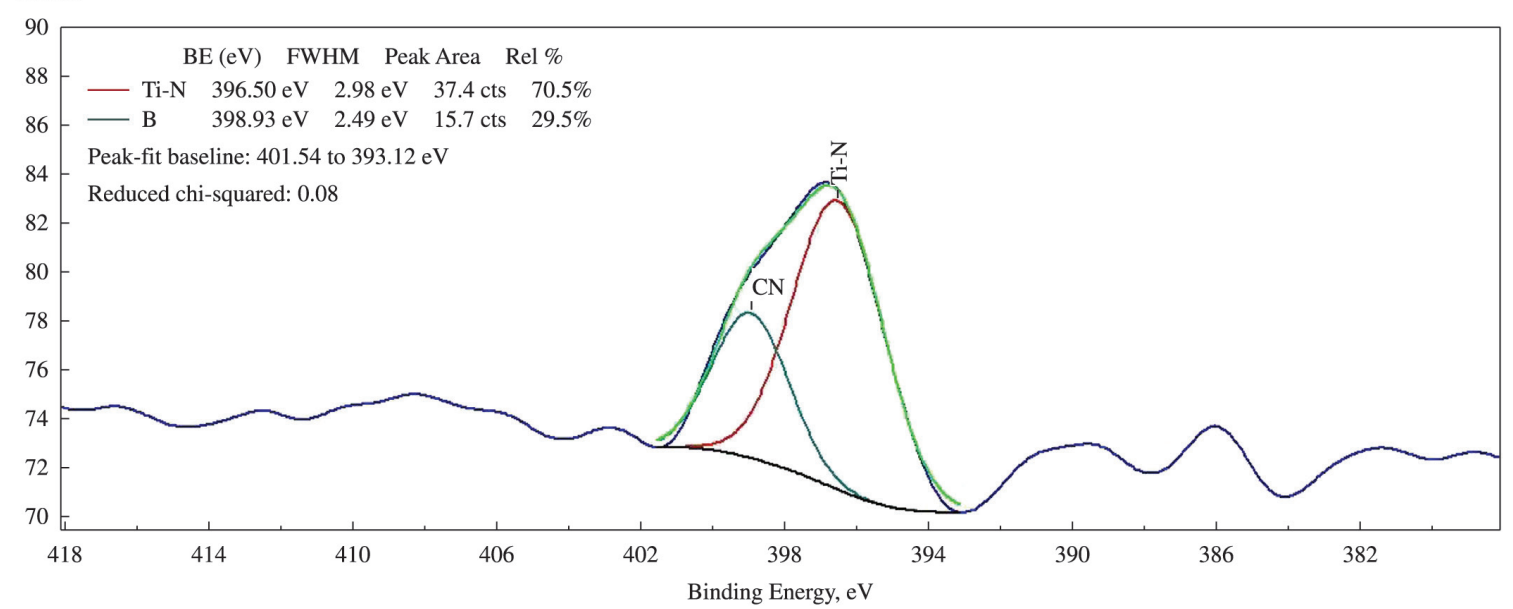

(b)

Counts

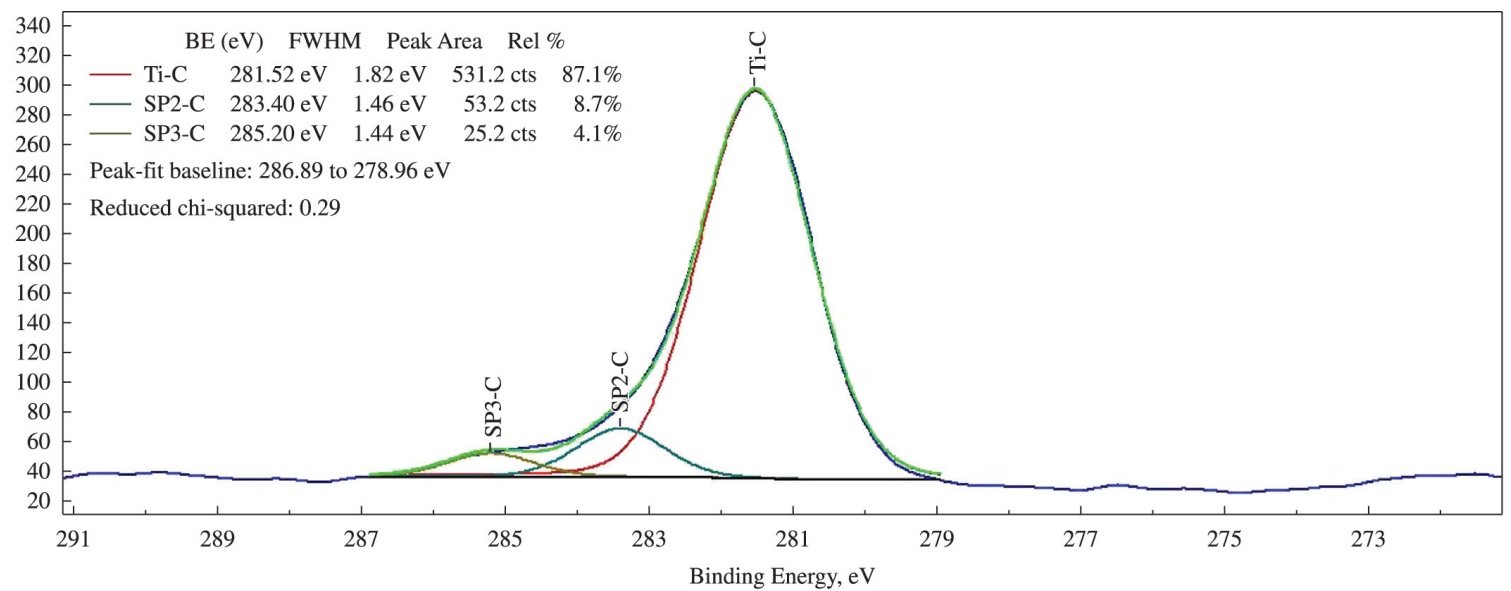

(c)

Figure 2. XPS spectra of a)Ti 2p, b)N 1s and c)C 1s for the film for $\mathrm{CH} 4 /(\mathrm{CH} 4+\mathrm{N} 2)$ gas flow ratio $66 \%$. 
the (200) plane in Figure 1b indicates that the grain size increases by increasing the flow ratio. Hence, the specific surface of TiCN decreases.

Only for a $\mathrm{CH}_{4} /\left(\mathrm{CH}_{4}+\mathrm{N}_{2}\right)$ gas flow ratio of 0.5 , the colour of the TiCN layers is brown. At higher gas flow ratio it becomes increasingly dark blue. This is in conformation to the investigation reported by E. Erturk et al. ${ }^{14}$.

The later layers mentioned are not stoichiometric. When the gas flow ratio was $\% 50$, the $\mathrm{C} / \mathrm{N}$ ratio was 0.43 with $\mathrm{TiC}_{30} \mathrm{~N}_{70}$ stoichiometric composition (Figure 1a). By

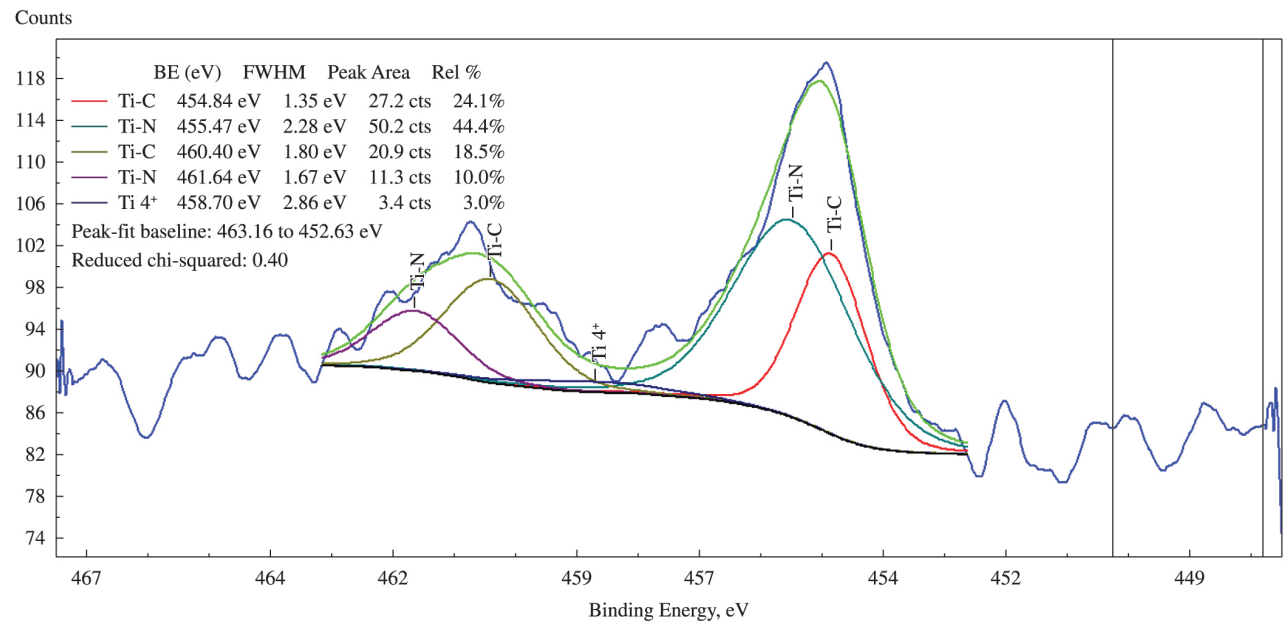

(a)

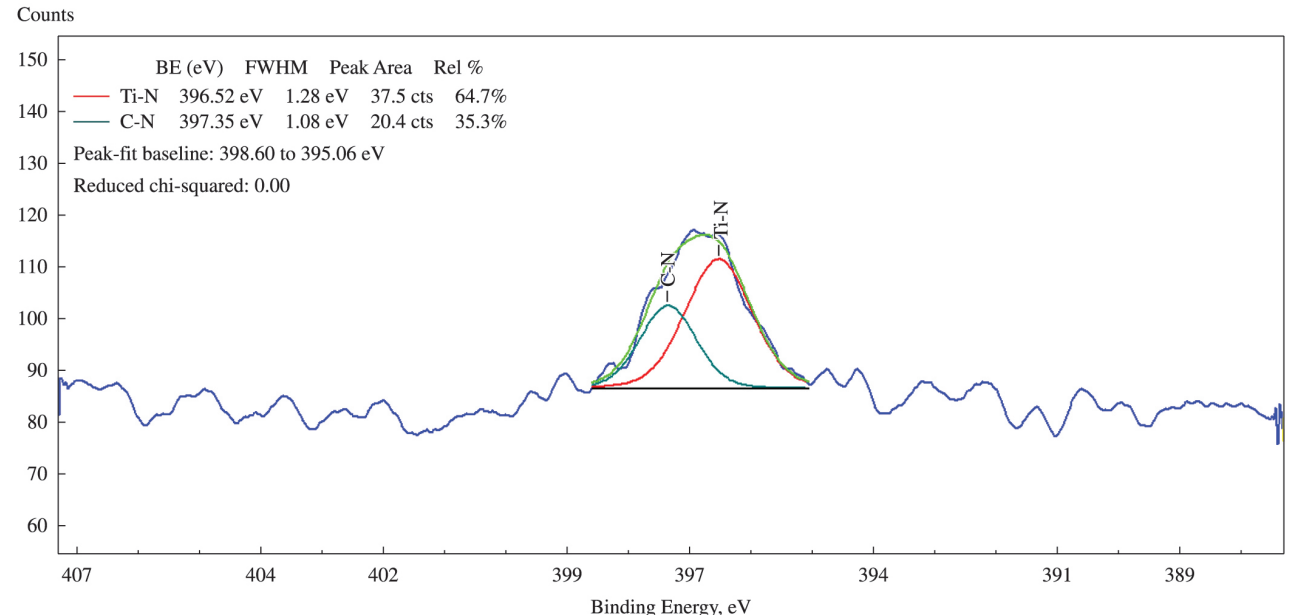

(b)

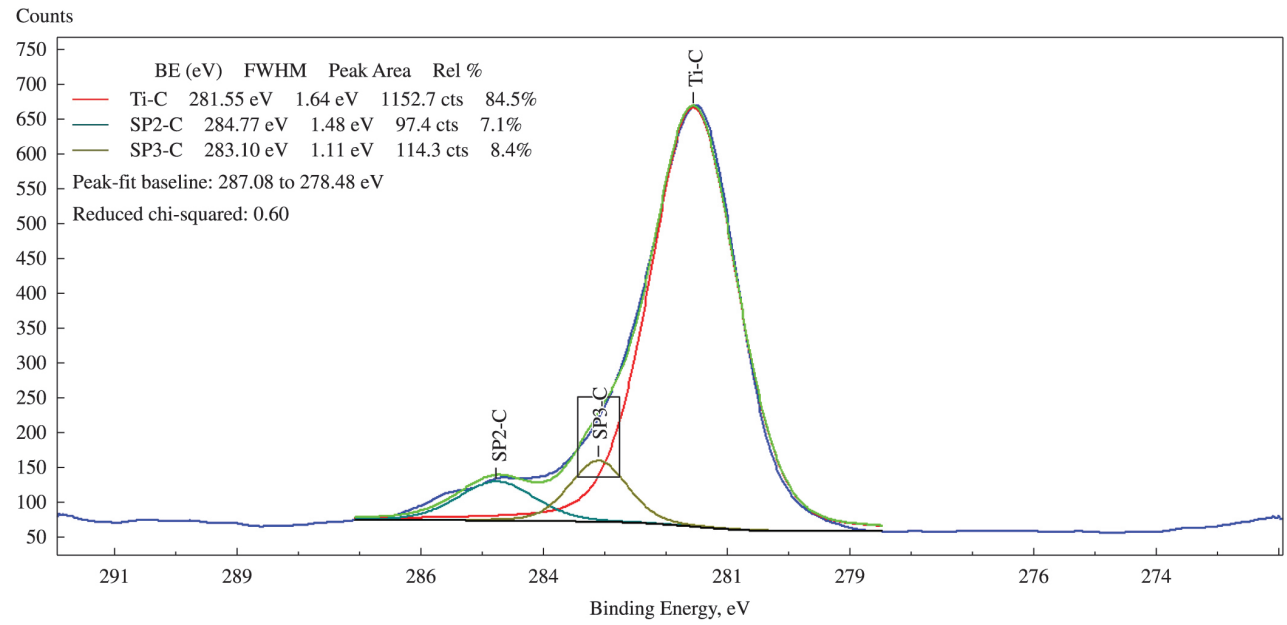

(c)

Figure 3. XPS spectra of a)Ti 2p, b)N 1s and c)C 1s for the film for $\mathrm{CH} 4 /(\mathrm{CH} 4+\mathrm{N} 2)$ gas flow ratio $50 \%$. 
increasing the gas flow ratio to $\% 66$, the $\mathrm{C} / \mathrm{N}$ ratio changed to 2.33 and $\mathrm{TiC}_{70} \mathrm{~N}_{30}$ stoichiometric composition (Figure 1b). The $\mathrm{TiC}_{30} \mathrm{~N}_{70}$ possesses a face-centered cubic (FCC) lattice with $\mathrm{a}_{\mathrm{o}}=0.4258 \mathrm{~nm}$ and grain size $28.6 \mathrm{~nm}$ but the $\mathrm{TiC}_{70} \mathrm{~N}_{30}$ possesses a face-centered cubic (FCC) lattice with $\mathrm{a}_{\mathrm{o}}=0.4287$ $\mathrm{nm}$ and grain size $44.37 \mathrm{~nm}$, so lattice parameter decreased with increasing gas flow ratio. This is in conformation to the relation (Equation 2) proposed by Li Yuanbing et al for $\mathrm{TiC}_{\mathrm{x}} \mathrm{N}_{1-\mathrm{x}}{ }^{[15]}$.

$$
a=0.4235+0.007 x(\mathrm{~nm})
$$

The residual stresses of the samples were determined by X-ray measurements. The surface residual stresses of TiCN layers were $-28.74 \mathrm{MPa}$ for $\% 66$ and $-23.42 \mathrm{MPa}$ for $\% 50$. The residual stress values increase with increasing the flow ratio.

The crystallite percents were determined by X-ray diffraction. The crystallite percents of TiCN layers were $\% 76$ for $\% 66$ gas flow ratio and $\% 85$ for $\% 50$. Also films deposited at low $\mathrm{CH}_{4} / \mathrm{N}_{2}$ ratios were much more crystallite than those deposited at high ratios.

Figure 2 presents the XPS spectra of Ti $2 p, N$ 1s and $\mathrm{C} 1 \mathrm{~s}$ of the TiCN film. In the Ti spectrum, two peaks of $\mathrm{Ti}$ $2 \mathrm{p}$ are found at 462.7 and $468.4 \mathrm{eV}$. The N 1s spectrum exhibits a weak peak at $394.6 \mathrm{eV}$, which corresponds to the $\mathrm{N}-\mathrm{Ti}$ bonds. The weak electronegative of $\mathrm{C}$ element, involves in the TiCN film formation, would slightly increase the binding energies of Ti-N. Cheng et al. ${ }^{16}$ have reported that the binding energy of the N 1s spectra of the TiCN films is lower than that of the TiN films. The $\mathrm{C} 1 \mathrm{~s}$ spectrum consists of three peaks at binding energies of 281.5, 283.4 and $285.2 \mathrm{eV}$. The peak at $281.5 \mathrm{eV}$ is assigned to the Ti-C bonds ${ }^{17}$. The peaks at $283.4 \mathrm{eV}$ and $285.2 \mathrm{eV}$ are assigned to the sp2-C and sp3-C bonds, respectively ${ }^{18}$. The $\mathrm{C} 1 \mathrm{~s}$ binding energies of pure graphite $(284.3 \mathrm{eV})$ and diamond $(285.3 \mathrm{eV})$ measured under the same conditions are cited for comparison.

It is also conveyed from Figures 2 and 3 that the peak at $281.5 \mathrm{eV}$ occupies a large fraction of the total C $1 \mathrm{~s}$ spectrum compared to the other peaks, indicating that a large fraction of $\mathrm{C}$ atoms are bonded to $\mathrm{Ti}$ atoms, and a little amount of $\mathrm{C}$ atoms exist as amorphous carbon. That is in conformation to GIXRD pattern.

Figure $2 \mathrm{a}$ shows that chemical composition is $\mathrm{TiC}_{0.426} \mathrm{~N}_{0.544} \mathrm{O}_{0.03}$ for $50 \%$ and $\mathrm{TiC}_{0.453} \mathrm{~N}_{0.51} \mathrm{O}_{0.038}$ for $66 \%$ (Figure 3). Therefore the XPS spectra offer similar chemical composition for both cases while they were different from GIXRD patterns because the XPS spectra are very sensitive to surface analysis.

SEM images show the thickness of layer plus the rate of growth, both of them decreased by increasing gas flow from $6.57 \mu \mathrm{m}$ to $4.83 \mu \mathrm{m}$. (Figure 4)

Figure 5 shows the AFM images of the TiCN layers. High $\mathrm{CH}_{4}$ gas flows led to a high surface roughness of the TiCN layers, as can be seen in the Figure $5 \mathrm{~b}$. A dense TiCN layer is grown in $50 \%$ but not in $66 \%$, where the TiCN layer has a relatively rough structure. According to Quirós et al. ${ }^{19}$, increasing roughness could be due to the fact that the assisting ions lead to significant damage and preferential sputtering effects, mainly during the deposition of the TiCN film. The effects are rather significant, inducing rougher surfaces and disappearance of the previous texture. Figure 5 shows that films deposited at low $\mathrm{CH}_{4} / \mathrm{N}_{2}$ ratios are much more homogeneous than those deposited at high ratios. Most of deposited particles size is around $55 \mathrm{~nm}$ at low $\mathrm{CH}_{4} / \mathrm{N}_{2}$ ratios while it is approximately $90 \mathrm{~nm}$ at low $\mathrm{CH}_{4} / \mathrm{N}_{2}$ ratios.

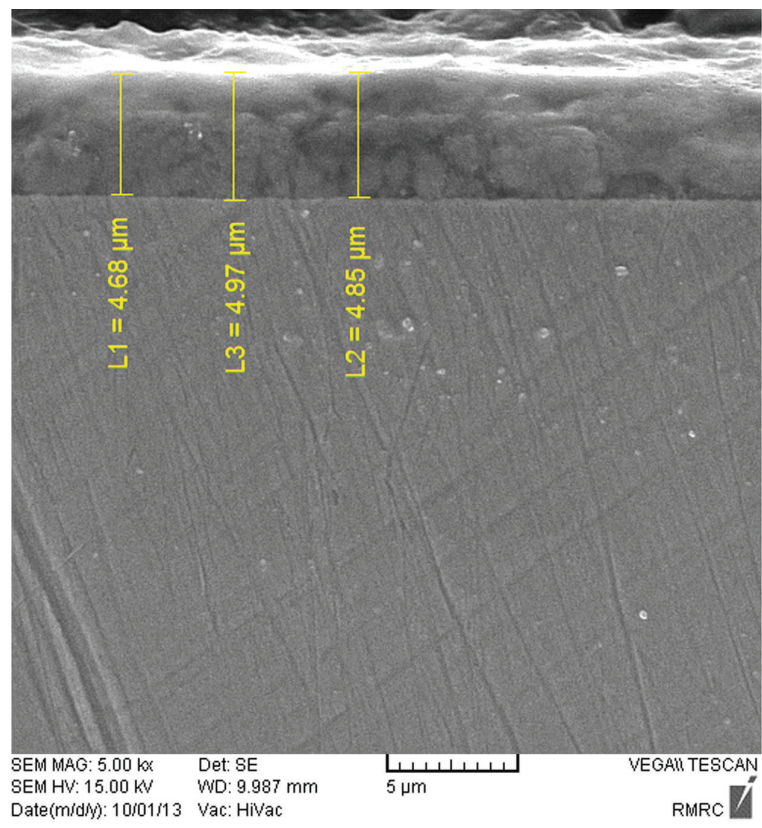

(a)

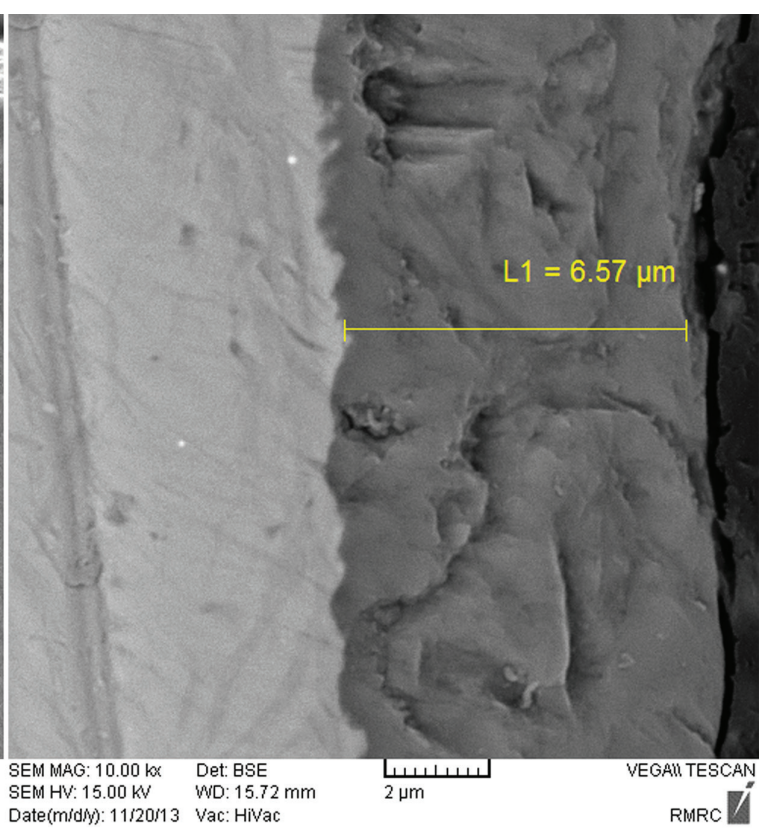

(b)

Figure 4. SEM images of deposited TiCN thin films for $\mathrm{CH} 4 /(\mathrm{CH} 4+\mathrm{N} 2)$ gas flow ratio a) $66 \%$ b) $50 \%$. 
The hardness values of TiCN coatings deposited at a temperature of $470{ }^{\circ} \mathrm{C}$ with various flow ratios are illustrated in Figure 6. A hardness value of $2038 \mathrm{HV}_{0.05}$ for the flow ratio of $50 \%$ to a hardness of $1896 \mathrm{HV}_{0.05}$ for the flow ratio of $66 \%$. It means that the hardness of the TiCN coatings decreased as the flow ratio increased. The reduction of hardness can be attributed to two reasons. When the flow ratio increases, the grain size of the TiCN coatings are increased (as shown in Figure 1), resulting a decrease in the hardness of TiCN coating. Furthermore, during the growth of the grain size, the chlorine atoms can diffuse into high angle grain boundaries, after exceeding the solubility limit of chlorine in the TiCN lattice ${ }^{20}$. Thus, the hardness of the thin films is decreased.
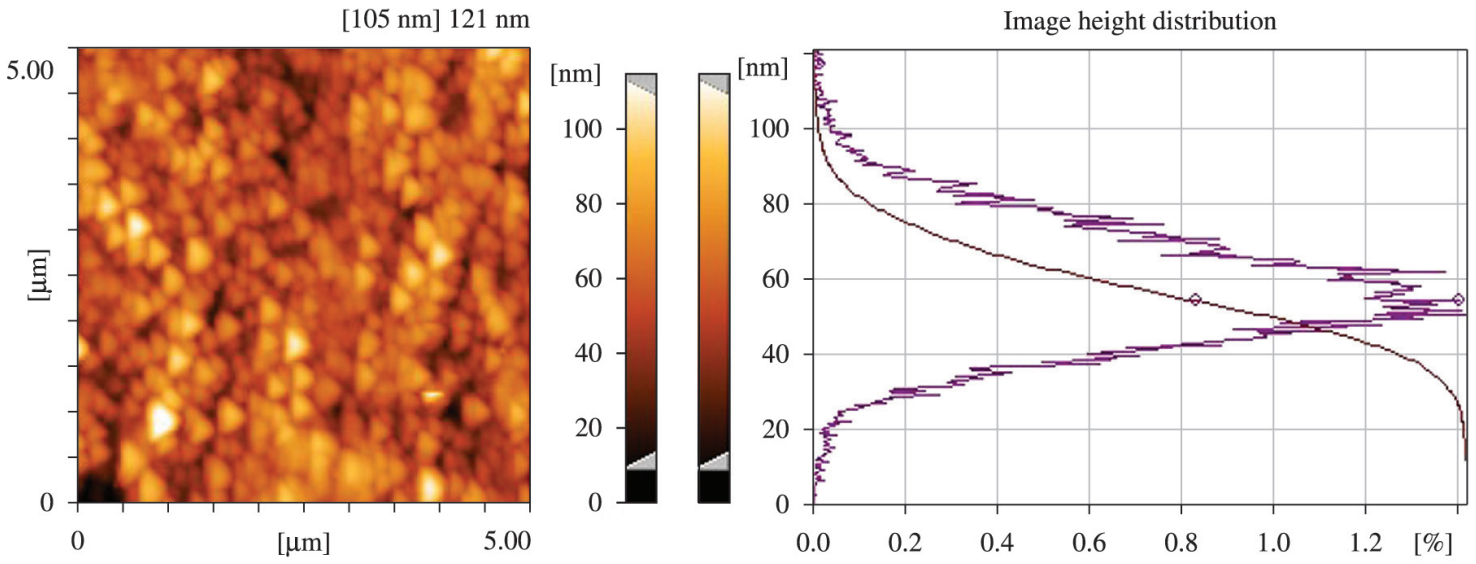

$[178 \mathrm{~nm}] 195 \mathrm{~nm}$
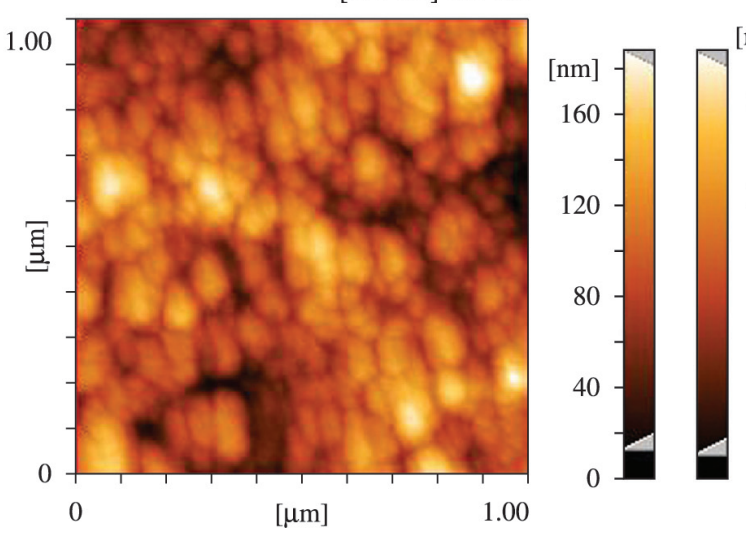

(a)

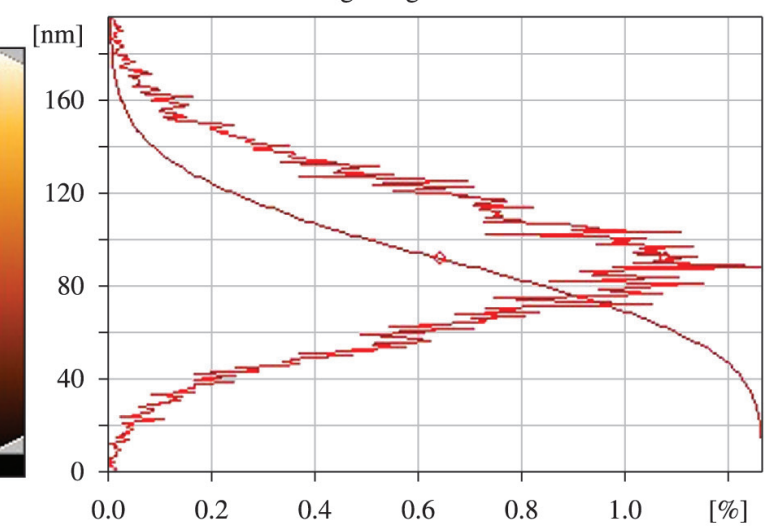

(b)

Figure 5. Morphology of TiCN thin films via the $\mathrm{CH} 4 /(\mathrm{CH} 4+\mathrm{N} 2)$ gas flow ratio, evaluated by AFM. a) $50 \%$ b) $66 \%$.

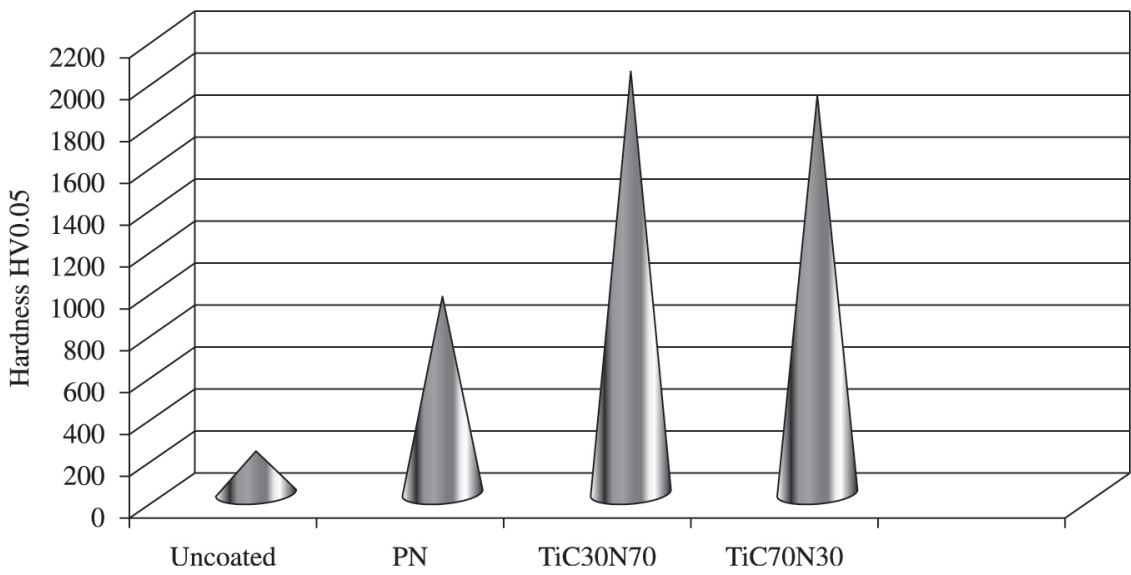

Figure 6. hardness values of TiCN coatings in various flow ratios. 


\section{Conclusion}

The following conclusions can be drawn from this research:

1- $\mathrm{TiC}_{30} \mathrm{~N}_{70}$ stoichiometric composition was obtained in 0.5 gas flow ratio and $\mathrm{TiC}_{70} \mathrm{~N}_{30}$ for 0.66 which were different from XPS results.

2-XPS peaks indicate that a large fraction of $\mathrm{C}$ atoms are bonded to Ti atoms, and a low fraction of $\mathrm{C}$ atoms exist as amorphous carbon.

\section{References}

1. Mebarki N, Delanges D, Lamesle P, Delmas F and Levaillant C. Relationship between microstructure and mechanical properties of a $5 \% \mathrm{Cr}$ tempered martensitic tool steel. Materials Science and Engineering A. 2004; 387-389:171-175. http://dx.doi. org/10.1016/j.msea.2004.02.073.

2. Barrau O, Boher C, Gras R and Rezai-Aria F. Analysis of the friction and wear behaviour of hot work tool steel for forging. Wear. 2003; 255(7-12):1444-1454. http://dx.doi.org/10.1016/ S0043-1648(03)00280-1.

3. Rie KT, Gebauer A, Wöhle J, Tönshoff HK and Blawit C. Synthesis of TiN/TiCN/TiC layer systems on steel and cermet substrates by PACVD. Surface and Coatings Technology. 1995; 74-75:375-381. http://dx.doi.org/10.1016/02578972(95)08243-3.

4. Hedenqvist P, Olsson M, Wallen P, Kassman A, Hogmark S and Jacobson S. How TiN coatings improve the performance of high speed steel cutting tools. Surface and Coatings Technology. 1990; 41(2):243-256. http://dx.doi.org/10.1016/02578972(90)90172-9.

5. Sundgren JE. Structure and properties of TiN coatings. Thin Solid Films. 1985; 128(1-2):21-44. http://dx.doi. org/10.1016/0040-6090(85)90333-5.

6. Kenneth L, Steve S, Jun Q and Paul S. Foreword from the Editors. Wear. 2009; 267(1-4):2142-2156. http://dx.doi. org/10.1016/j.wear.2009.04.001.

7. Rie KT, Gebauer A and Woehle J. Investigation of PACVD of TiN: Relations between process parameters, spectroscopic measurements and layer properties. Surface and Coatings Technology. 1993; 60(1-3):385-388. http://dx.doi. org/10.1016/0257-8972(93)90118-8.

8. Ishii Y, Ohtsu H, Adachi T, Ichimura H and Kobayashi K. TiN film formation by plasma chemical vapor deposition and its plasma diagnostics. Surface and Coatings Technology. 1991; 49(1-3):279-283. http://dx.doi.org/10.1016/02578972(91)90069-9.

9. Zhang H, Yan D and Tang S. Preparation and properties of ultrafine TiCN matrix cermets by vacuum microwave sintering. Rare Metals. 2010; 29(5):528-532. http://dx.doi.org/10.1007/ s12598-010-0162-8.

10. Cullity BD. Elements of X-ray Diffraction. 2nd ed. Reading: Addison Wesley; 1978.

11. Niederhofer A, Bolom T, Nesladek P, Moto K, Eggs C, Patil DS, et al. The role of percolation threshold for the control
3-The films grown, using plasma-assisted processes at lower flow ratios were generally fine-grained and had a denser structure.

4-It was found that the growth rate decreased with increasing the flow ratio.

5-Finally, it was found that the surface hardness decreased with increasing the flow ratio due to decrease in grain size and diffusion of chlorine in grain boundary.

of the hardness and thermal stability of super- and ultrahard nanocomposites. Surface and Coatings Technology. 2001; 183:146-147.

12. Barker MG, Alexander IC and Bentham J. The reactions of liquid lithium with the dioxides of titanium, zirconium, hafnium and thorium. Journal of the Less Common Metals. 1975; 42(2):241-247. http://dx.doi.org/10.1016/00225088(75)90010-7.

13. Klemberg-Sapieha JE, Jedrzejowski P and Martinu LJ. Mechanical and optical characteristics of superhard nanocomposite TiN/a-Si3N4 and TiCN/a-SiCN coatings produced by PECVD. Superhard Mater. 2007; 29(3):147-152. http://dx.doi.org/10.3103/S1063457607030069.

14. Ertürk E, Knotek O, Burgmer W, Prengel HG, Heuve HJ, Dederichs $\mathrm{HG}$, et al. Ti(C,N) coatings using the arc process. Surface and Coatings Technology. 1991; 46(1):39-46. http:// dx.doi.org/10.1016/0257-8972(91)90148-P.

15. Yuanbing L, Nan L, Guozhi R, Jianwei L and Xiaohui L. Effects of technical factors on MgAl2O4-TiN composites produced by aluminothermic reduction and nitridation. Materials \& Design. 2007; 28(3):969-972. http://dx.doi.org/10.1016/j. matdes.2005.10.006.

16. Cheng YH, Browne T and Heckerman B. Influence of $\mathrm{CH} 4$ fraction on the composition, structure, and internal stress of the TiCN coatings deposited by LAFAD technique. Vacuum. 2010; 85(1):89-94. http://dx.doi.org/10.1016/j.vacuum.2010.04.007.

17. Meng J, Lu J, Wang J and Yang S. Tribological behavior of TiCN-based cermets at elevated temperatures. Materials Science and Engineering A. 2006; 418(1-2):68-76. http:// dx.doi.org/10.1016/j.msea.2005.11.022.

18. Jiang JL, Hao JY, Pang XJ, Wang P and Liu WM. Structure and characteristics of amorphous (Ti,Si)-C:H films deposited by reactive magnetron sputtering. Diamond and Related Materials. 2010; 19(10):1172-1177. http://dx.doi.org/10.1016/j. diamond.2010.05.005.

19. Quirós C, Prieto P, Fernández A, Elizalde E, Morant C, Schlögl $\mathrm{R}$, et al. Bonding and morphology study of carbon nitride films obtained by dual ion beam sputtering. Journal of Vacuum Science \& Technology. A, Vacuum, Surfaces, and Films. 2000; 18(2):515. http://dx.doi.org/10.1116/1.582218.

20. Stoiber M, Badisch E, Lugmair C and Mitterer C. Low-friction TiN coatings deposited by PACVD. Surface and Coatings Technology. 2003; 163-164:451-456. http://dx.doi.org/10.1016/ S0257-8972(02)00642-4. 